\title{
A Detergent Destruction Method Used for Aerobic Treatment of Wastewater High in Detergent Content (WHD)
}

\author{
K. N. Tan
}

\begin{abstract}
Detergent removal from wastewater treatment is important for environmental protection. Biosorption of detergent onto the activated sludge enables aerobic treatment of the wastewater. This paper presents a further improvement of the method by a massive destruction of the detergent through a prolonged mixing of the detergent with the activated sludge prior to the aeration process. This is possible as detergent is a cleaning agent and can breakdown the activated sludge through intimate contact in the mixing process. Thickening of the activated sludge and culturing activated sludge with high biosorption capacity ensures the intimate contact for the detergent destruction action. Breaking down of the activated sludge provides a high loading condition which favors the growth of microorganism with strong biosorption capacity. The method was successfully implemented in the detergent packing plant.
\end{abstract}

Index Terms - Wastewater, aeration, detergent destruction.

\section{INTRODUCTION}

Detergent content in wastewater contributes to water pollution. Recent survey has shown significant accumulation of the surfactants in sediments near to the discharge area of large sewage treatment plants jeopardizing the aquatic ecosystem [1]. In water reclamation plants engaging membrane technology, cummulation of detergent content on membrane surface causes fouling of the membrane filters [2]. This has adversely affected the filtration operation.

Present of detergent in wastewater causes difficulty in traditional wastewater treatment and detergent removal has been of keen research interest recently [3].There are many studies on treatment of the detergent wastewater such as Fenton.

Oxidation [4] and wet air oxidation [5]. Wet air oxidation of the Linear alkyl benzene sulfonate (LAS) was able to breakdown the detergent molecules into short alkyl chains which do not behave as active detergent. However the oxidized detergent compounds were not as biodegradable as the original LAS.A recent report has revealed a high efficiency in degrading LAS using an electrolysis method with the addition of $\mathrm{Fe} 2+$ ions [6]. Wastewater high in detergent (WHD) is actually a high strength wastewater usually treated by anaerobic digestion [7].Detergent wastewater treated by the Up-Flow Anaerobic Sludge Blanket reactor followed by the Activated Sludge Process (ASP) had a

Manuscript received April 12, 2019; revised May 23, 2019.

K. N. Tan with M/s D\&R Chemicals, Sugei Kadut Street 1, Singapore (e-mail: tankokngee@gmail.com).
89-92\% removal of the anionic surfactants (AS) [8].Yet the aerobic post treatment still need further modification to reduce the AS to a level having no risk to the aquatic environment.

Being efficient, ecological and cost effective, aerobic wastewater treatment is always the preferred treatment method. However extensive detergent foam is generated when WHD is aerated in the ASP. Elimination of detergent content from the wastewater can be of use for aerobic wastewater treatment. This can be done by physical adsorption to remove the detergent from the wastewater. Zeolite and granular activated carbon can be used as physical adsorbent prior to the aeration [9].

Activated sludge is actually a good biological adsorbent. It has been reported that LAS was strongly and easily adsorbed onto the activated sludge [10].The adsorption was found to be $92-98 \%$ of the detergent content in the mixed liquor.

This paper presents an improvement to the bio-sorption method used to treat WHD. A detergent destruction method was designed to enable aerobic treatment of a much larger quantity of the WHD.

\section{MethodS AND MATERIALS}

\section{A. Principles of Method Used}

In the adsorption method detergent is adsorbed onto the activated sludge before the AERATE stage, hence preventing severe foaming while treating the WHD aerobically in a Sequencing Batch Reactor (SBR) [11]

To ensure an almost complete detergent adsorption, it is necessary to thicken the activated sludge cultured with strong adsorption capacity. For this purpose, an adsorption tank is included in the reactor system as shown in Fig. 1.

For the detergent destruction method, the detergent is further broken down or destroyed prior to the AERATE stage. The massive destruction of the detergent enables aerobic treatment of a much larger quantity of WHD.

The reactor system was modified with addition of the adsorption tank in the SBR reactor system as reported in the adsorption method for WHD treatment [11].The detergent destruction method has adopted the same reactor system but with the modification of the SBR process by including

The SBR has therefore the following stages per cycle.

FILL

DESTRUCTION

AERATE 
SETTLE

DECANT

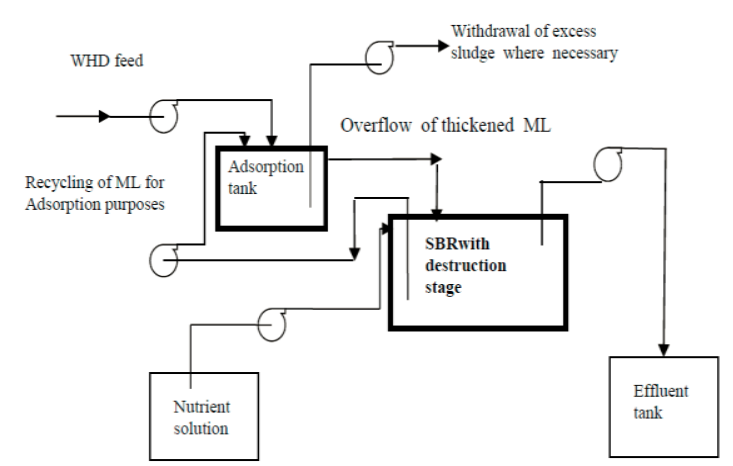

Fig. 1. Reactor set-up for SBR with adsorption tank.

\section{B. Method of Treatment}

Schematic flow diagram for the SBR system operated with the detergent destruction method is given in Fig. 1.

Mixed liquor is continuously recycled into the adsorption tank which is level control ie what flows in will overflow back to the aeration tank. The adsorption tank is not aerated throughout and is ONLY agitated when feeding with WHD. Hence there is deposition and cumulation of the activated sludge in the adsorption tank.

For a cycle of SBR operation, WHD is fed in the FILL stage. WHD enters the aeration tank through the adsorption tank which then has a very high activated sludge concentration through the thickening process before the FILL stage.

At the end of the FILL stage, the DESTRUCTION stage takes place with agitation in both the adsorption tank and the aeration tank without aeration. With the continuous recycle of the mixed liquor, there is some degree of sludge depositi The DESTRUCTION stage therefore prolongs the mixing of the detergent and the activated sludge prior to the AERATE stage facilitating destruction of the detergent.

With the AERATE, SETTLE and DECANT stages to complete the cycle of operation of the SBR, the WHD can then be treated with much reduction in COD and almost complete detergent removal as there is no foaming occurring in the AERATE stage.

\section{Materials}

The wastewater is produced from cleaning of the used containers returned from customers. Tap water is used and hence the wastewater is actually the washing water and is highly deficient in basic carbonaceous sources and the nutrients for cell growth. Depending on the level of Mixed Liquor Suspended Solids (MLSS), sugar or other simple food waste are

Basic nutrients supplement and, in particulars, nitrogenous and phosphoric compounds are added. Urea and potassium hydrogen phosphates are used. List of nutrients and relative quantities are given in Table I.

As explained in the reactors operation later, most of the nutrients supplements, except the urea are being conserved and reused and needs only a small quantity of replenishment. Hence, only nitrogenous and the carbonaceous sources are frequently added.
TABLE I: NUTRIENTS SUPPLEMENT FOR SBR COMPOSITION OF TRACE ELEMENT SOLUTION

\begin{tabular}{|l|l|}
\hline & $\mathrm{Kg} / \mathrm{m} 3$ \\
\hline $\mathrm{MgSO} 4.7 \mathrm{H} 2 \mathrm{O}$ & 5 \\
\hline $\mathrm{FeCl} 3.6 \mathrm{H} 2 \mathrm{O}$ & 7 \\
\hline Boric Acid & 0.001 \\
\hline $\mathrm{CuSO} 4.5 \mathrm{H} 2 \mathrm{O}$ & 0.001 \\
\hline (NH4)6Mo7O24.4H2O & 0.550 \\
\hline $\mathrm{NaCl}$ & 1 \\
\hline $\mathrm{CaCl} 2.6 \mathrm{H} 2 \mathrm{O}$ & 2 \\
\hline $\begin{array}{l}\text { Urea: } 0.6 \mathrm{~kg} / \mathrm{m}^{3} \\
\text { Di-Potassium hydrogen phosphate: } 0.6 \mathrm{~kg} / \mathrm{m}^{3} \\
\text { Trace element solution: } 1 \mathrm{~L} / \mathrm{m}^{3}\end{array}$ \\
\hline
\end{tabular}

\section{Plant Operation}

The detergent factory generates $800 \mathrm{~L}$ to $1000 \mathrm{~L}$ of washing water per day with Chemical Oxygen Demand (COD) ranging from 2000 to $4000 \mathrm{mg} / \mathrm{L}$. The SBR is operated with a 12 hours cycles with the the following stages:

FILL: 2 hours

DESTRUCTION: 2 hour

AERATE: 6 hours

SETTLE: 1.5 hours

DECANT: 0.5 hours

As explained earlier, WHD is fed through the adsorption tank. In the FILL stage, WHD is fed intermittently with 5 minutes break interval throughout the complete feeding time of 2 hours. A typical feeding rate can be 15 mins feeding/5 mins breaks. The break intervals are to enable some build-up of activated sludge as the feeding will dilute the sludge content. The feeding rate is adjusted for the complete delivery of the WHD volume to be treated. Even though 2 hours are assigned to the DESTRUCTION stage, the total 4 hours of FILL and DESTRUCTION are actually having the destructive action as there is continuous and strong agitation taking place at the same time. Carbonaceous source and nutrients supplement are being added during the FILL stage.

The detergent destruction method differs from the adsorption method by having a prolonged mixing after feeding the WHD to induce a massive destruction of the detergent content prior to the aeration process. Two factors are particularly important to achieve a near complete destruction of the detergent.

Firstly, an effective sludge thickening in the adsorption tank and secondly, the activated sludge should be cultured with high adsorption capacity.

Sludge thickening will result in larger quantity of the activated sludge interacting with the detergent when the WHD enters the adsorption tank. Detergent is a cleaning agent and will clean up the dirt, in this case the activated sludge, when the two are brought intimately together. Close contact of the detergent with the activated sludge is therefore similar to the fact that rubbing or mechanical friction needs to be applied for washing with detergent, much the same as the strong agitation designed for the operation of washing machine.

It should be noted that longer duration of FILL and 
DESTRUCTION stages have achieved a certain degree of COD removal through fermentation. Earlier research had revealed that with prolong FILL stage in an SBR, there was up to $86 \%$ of BOD (Biological oxygen demand) reduction caused by fermentation [12]. With detergent, such reduction is even higher as it has the cleaning effect and is therefore consumed or inactivated while "cleaning up" the activated sludge. This is in fact a self destruction action.

Activated sludge having stronger adsorption capacity is yet another important factor speeding up the detergent destruction process. Most certainly, detergent molecules are more promptly adsorbed onto activated sludge with higher adsorption capacity to begin with its destruction action.

Activated sludge can be cultured with strong adsorption capacity by effective aeration and high loading condition.

Activated sludge follows aerobic metaboism and will be active with adequate air supply and efficient aeration process. Duration of aeration can siginicantly affect bio-sorption capacity of the activated sludge. While normal activated sludge process failed to treat the toxic substance of 2,4-dimethylphenol (DMP), prolong aeration of the activated sludge up to 50 days had been found capable of removing $40 \%$ of the toxic substance from a $50 \mathrm{mgDMP} / \mathrm{L}$ solution with $1 \mathrm{gMLSS} / \mathrm{L}$, just because of the much stronger bio-sorption capacity of activated sludge cultured [13]

Activated sludge consists of different types of aerobic micro-organisms. It was known that high Biological Oxygen Demand (BOD) loading favors the growth of floc former [14] Immediately after the DESTUCTION stage, there will be a large quantity of smaller hydrocarbons released from the cleavage of microbial cells. This creates a high loading condition for the following AERATE stage. Hence, other than prevention of foaming, destruction of the detergent also induces the growth of micro-organisms with higher bio-sorption capacity.

\section{RESUlTS AND DisCUSSION}

\section{A. The Bio-sorption Method vs Detergent Destruction Method}

With bio-sorption to prevent detergent foaming, the SBR was under normal operation treating WHD aerobically without foaming. The detergent destruction method is similar to the bio-sorption method but increases treatment capacity with an additional stage of DESTRUCTION in the SBR. Comparison of operational and analytical data for both methods is given in Table II

\section{B. Fig. 2 to 6 Show the Condition of the Reactor with Detergent Destruction Method}

In Fig. 2 severe foaming occurred during AERATE stage. Double or triple volume of WHD were added to SBR through the adsorption tank during the FILL stage.

Aeration started, skipping the DESTRUCTION stage, detergent foaming occured instantly and extensively. The operation has to stop to include a mixing only DESTRUCTION stage. The reactor was then continued with normal operation of SBR.
TABLE II: NUTRIENTS SUPPLEMENT FOR SBR COMPOSITION OF TRACE ELEMENT SOLUTION

\begin{tabular}{|l|l|l|}
\hline & Biosorption method & $\begin{array}{l}\text { Detergent Destruction } \\
\text { Method }\end{array}$ \\
\hline $\begin{array}{l}\text { Total WHD } \\
\text { treated per } \\
\text { cycle }\end{array}$ & $200 \mathrm{~L}$ & $600 \mathrm{~L}$ \\
\hline $\begin{array}{l}\text { No of cycles } \\
\text { per day }\end{array}$ & 2 & 2 \\
\hline $\begin{array}{l}\text { No of } \\
\text { reactor in } \\
\text { operation } \\
\text { per day }\end{array}$ & 2 & 1 \\
\hline $\begin{array}{l}\text { Total WHD } \\
\text { treated per } \\
\text { day }\end{array}$ & $800 \mathrm{~L}$ & $1200 \mathrm{~L}$ \\
\hline $\begin{array}{l}\text { COD of } \\
\text { WHD }\end{array}$ & $2000-4000 \mathrm{mg} / \mathrm{L}$ & $2000-400 \mathrm{mg} / \mathrm{L}$ \\
\hline $\begin{array}{l}\text { COD of } \\
\text { effluent }\end{array}$ & $300-600 \mathrm{mg} / \mathrm{L}$ & $300-600 \mathrm{mg} / \mathrm{L}$ \\
\hline $\begin{array}{l}\text { Average } \\
\text { MLSS }\end{array}$ & $2000 \mathrm{mg} / \mathrm{L}$ & $2000 \mathrm{mg} / \mathrm{L}$ \\
\hline Reactor size & $1.2 \mathrm{mx} 2.4 \mathrm{mx} 1.2 \mathrm{~m}$ & $1.2 \mathrm{mx} 2.4 \mathrm{mx} 1.2 \mathrm{~m}$ \\
\hline
\end{tabular}

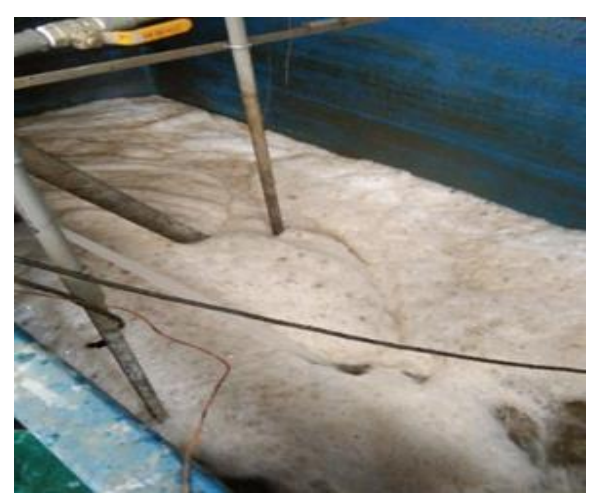

Fig. 2. Severe foaming when aerating without DESTRUCTIVE stage.

Fig. 3 shows DETRUCTION stage with mixing and no aeration. There was no detergent foam as expected without aeration. Fig. 4 shows the SBR in AERATE stage following DESTRUCTION stage, normal operation, without detergent foaming was observed throughout the AERATE stage.

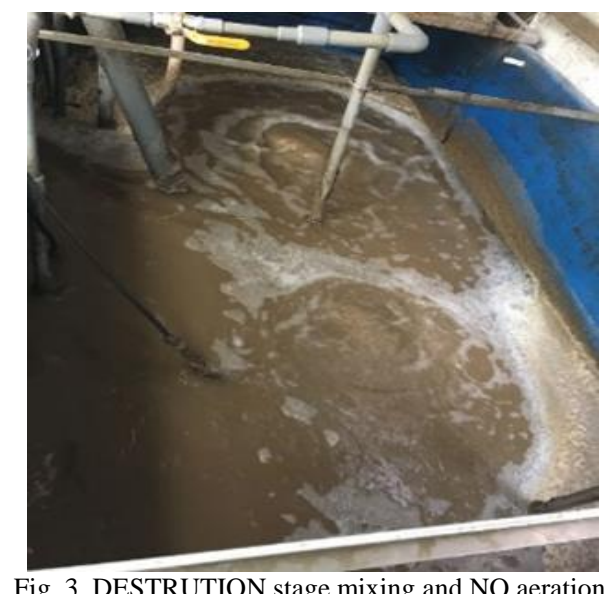

Fig. 5 shows prominent foaming in the AERATE stage even with the DESTRUCTION stage in the SBR. This occured when there was incomplete destruction of the detergent content. The very small amount of detergent present causes mild foaming. Near to end of the AERATE 
stage, foaming was much reduced in Fig. 6.This shows that the trace amount of the detergent could have been removed during the aeration and the mixing in the AERATE stage.

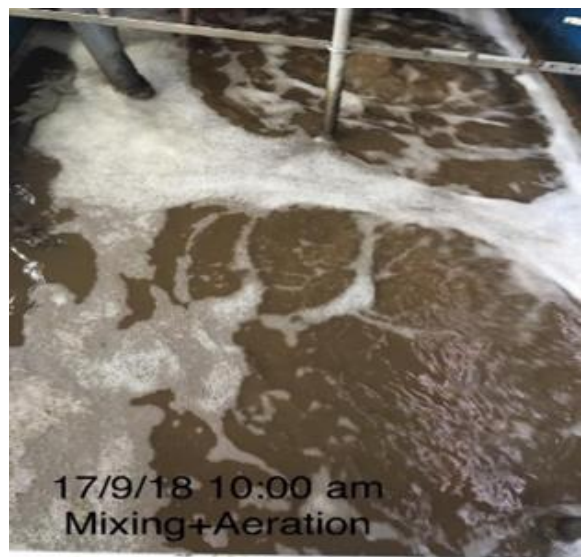

Fig. 4. AERATE stage mixing and aeration. NO detergent foaming.

It should be noted that moderate foaming can also occur when there is inadequate activated sludge for detergent destruction or less adsorptive activated sludge present in the SBR.

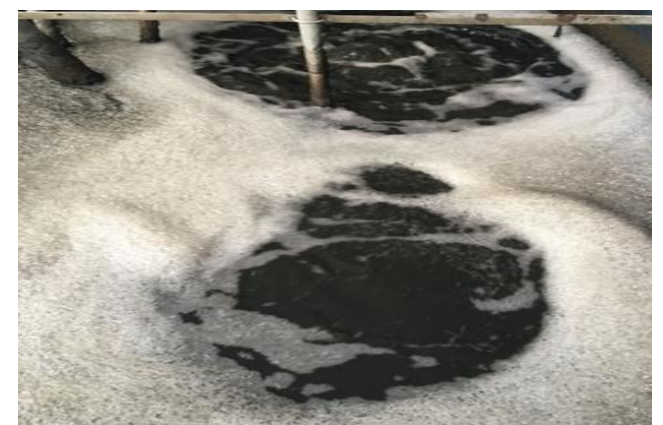

Fig. 5. AERATE stage with incomplete detergent destruction in DESTRUTION stage.

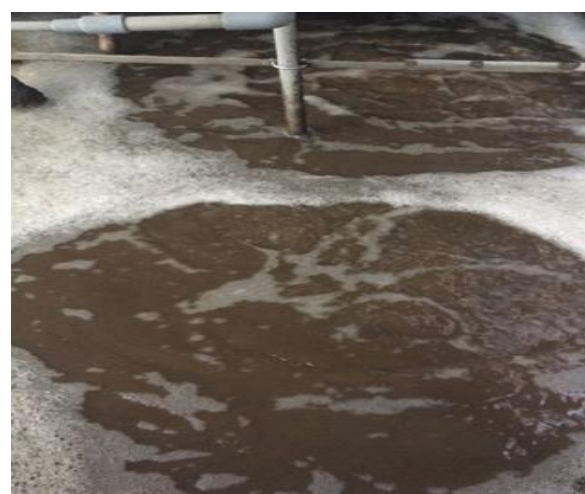

Fig. 6. Much reduced foaming near to end of AERATE stage.

\section{CONCLUSION}

By taking advantage of the detergent being a cleaning agent, the detergent destruction method has enabled aerobic treatment of a much larger quantity of WHD. The method has also tactically employs sludge regeneration with the re-use of cell decay products for re-building of fresh activated sludge avoiding massive use of trace elements which can be yet another source of pollution.

Abbreviations
AS: Anionic surfactants

ASP: Activated Sludge Process

BOD: Biological Oxygen Demand

COD: Chemical Oxygen Demand

DMP: 2,4-dimethylphenol

LAS: Linear alkybenzene sulfonate

MLSS: Mixed Liquour Suspended solids

SBR: Sequencing batch reactor

WHD: Wastewater high in detergent content

The SI unit for magnetic field strength $H$ is $\mathrm{A} / \mathrm{m}$. However, if you wish to use units of $\mathrm{T}$, either refer to magnetic flux density $B$ or magnetic field strength symbolized as $\mu_{0} H$. Use the center dot to separate compound units, e.g., "A $\cdot \mathrm{m}^{2}$."

\section{CONFLICT OF INTEREST}

The authors declare no conflict of interest.

\section{AUTHOR CONTRIBUTIONS}

I am the sole author.

\section{REFERENCES}

[1] X. L. Li, A. C. Doherty, B. Brownawell, and P. A. L. Martin "Distribution and diagenetic fate of synthetic surfactants and their metabolites in sewage-impacted estuarine sediments," Environmental Pollution, vol. 242, Part A, pp. 209-218, Nov. 2018.

[2] Z. Mai, V. Butin, M. Rakib, H. Zhu, M. Rabiller, Baudry, and E. Couallier, "Influence of bulk concentration on the organisation of molecules at a membrane surface and flux decline during reverse osmosis of an anionic surfactant," J.Membrane Science, vol. 499, pp 257-268, February 2016

[3] M. Palmer and H. Hatley, "The role of surfactants in wastewater treatment: Impact, removal and future techniques: A critical review," Water Research, vol. 147, pp. 60-72, December 2018

[4] Sheng, H. Lianachi, M. L. Horng, and G. Leub, "Operating characteristics and kinetic studies of surfactant wastewater treatment by Fenton oxidation," Water Research, vol. 33, issue. 7, pp. 1735-1741, May 1999.

[5] D. Mantzavinos, D. M P. Burrows, R. Willey, G. L. Biundo, S. F. Zhang, A. G. Livinston, and I. S. Metcalfe, "Chemical treatment of an anionic surfactant wastewater: electrospray-ms studies of intermediates and effect on aerobic biodegradability," Water Research, vol. 35, issue 14, pp. 3337-3344, October 2001.

[6] T. S. Budikania, C. Irawan, K. Afriani, Foliatini, and N. Saksono, "Degradation of linear alkylbenzene sulfonate (LAS) by using multi-contact glow discharge electrolysis (m-CGDE) and Fe2+ ion as catalyst," J. Environmental Chemical Engineering, vol. 5 issue 3, pp. 2346-2349, June 2017.

[7] Rania, A. H. Oliver, Ternalorhemen, and J. W. Tay, "Advances in biological systems for the treatment of high-strength wastewater," $J$ Water Process Engineering, vol. 10, pp. 128-142, April 2016.

[8] A. K. Mungray and Z. V. P. Murthy, "Post-treatment of up-flow anaerobic sludge blanket reactor effluents in activated sludge process-based system for anionic surfactants," J. Water and Environment, vol. 28, issue 1, pp. 84-94, March 2014

[9] S. Hanan and A. E. Gawad, "Aquatic environmental monitoring and removal efficiency of detergents," Water Science, vol. 28, issue. 1, pp. 51-64, October 2014.

[10] H. T. B. Klapwijk, "Fate of linear alkylbenzene sulfonate (LAS) in activated sludge plants," Water Research, vol. 38 issue 4, pp. 903-912, February 2004.

[11] K. N. Tan, "Use of concept of bio-sorption in an Aerobic treatment of wastewater rich in detergent content," Presented at the 27th Conference of ASEAN Federation of Enginieering Organisation, 2009.

[12] W. J. Ng, T. S. Sim, S. L. Ong, K. Y. Ng, M. Ramasamy, and K. N. Tan, "Efficiency of sequencing batch reactor (SBR) in the removal of selected microorganisms from domestic sewage," Water Research, vol. 27, issue 10, pp. 1591-1600, October 1993.

[13] H. Gulyas, U. Heldtl, and Sekoulov, "The sorption capacity of long-time aerated activated sludge demonstrated with 2,6-dimethylphenol," Water Science and Technology, vol. 39, issue 8, pp. 131-138, 1999. 
[14] L. Metcalf and H. P. Eddy, Wastewater Engineering: Collection, Treatment, McGraw-Hill, Inc. NY, 2004, pp. 700-703.

Copyright $\odot 2019$ by the authors. This is an open access article distributed under the Creative Commons Attribution License which permits unrestricted use, distribution, and reproduction in any medium, provided the original work is properly cited (CC BY 4.0).

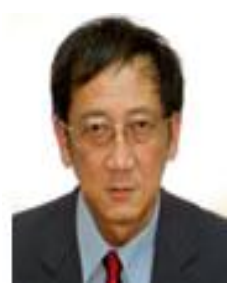

Tan Kok Ngee obtained his B.Sc.(Hons) (applied chemistry) in 1974 and the M.Eng (chemical) in 1995, both from National University of Singapore. He was a senior process chemist in sewage treatment works of the Ministry of the Environment Singapore for 19 years and in water reclamation plants of the Public Utilities Board Singapore for 5 years. He was responsible for the direction of process management and control of various sewage and sludge treatment units, specializing in problems solving like Nocardia foaming and process improvement like enhanced biogas production.In 2005 he went into private practice and is currently, Senior Consultant, KN Tan Enviro Technologist for domestic and industrial wastewater treatment.

He had published several papers on international conferences and journals reporting on the theoretical aspects of behaviors of process units. Currently he is working on decentralized small wastewater treatment plants for small town and communities and is developing a method for the production of super clear effluent, free from suspended solids, based on classical hydraulic theories. 